\title{
A inserção da regulamentação da profissão na área de Educação Física, dez anos depois: embates, debates e perspectivas
}

\author{
Marco Antonio Bettine de Almeida* \\ Paulo César Montagner ${ }^{* *}$
}

Gustavo Luis Gutierrez ${ }^{* * *}$

\begin{abstract}
Resumo: Este texto discute alguns aspectos da regulamentação da profissão na área da Educação Física, seu desenvolvimento e a participação dos principais sujeitos políticos. Frente a um tema atual e polêmico, procura-se fazer uma apresentação objetiva e abrangente do seu desenvolvimento e ilustrar as posições e os argumentos dos sujeitos que participam do debate. Para tanto, inicia-se apresentando aspectos importantes da regulamentação das profissões, para depois elaborar uma análise da lei e resoluções do Conselho destacando: (a) o seu significado; (b) atribuições e competências; (c) o limite para a fiscalização e do poder de policia e (d) apontar as atividades típicas do profissional. A título de fechamento, descreve-se aspectos de uma polêmica bastante recente, a subordinação da dança, da yoga $e$ das artes marciais ao Conselho Federal de Educação Física.
\end{abstract}

Palavras-chave: Prática profissional. Educação Física. ConseIhos de especialidade profissional

\section{INTRODUÇÃo}

A discussão de temas atuais e polêmicos, como é caso do desenvolvimento do Conselho Federal de Educação Física (CONFEF), apresenta algumas dificuldades adicionais à pesquisa. Em primeiro lugar, nem sempre é fácil distinguir os acontecimentos e sujeitos

\footnotetext{
'Professor, na Escola de Educação Física e Esporte de Ribeirão Preto. (Doutor). Universidade de São Paulo. Ribeirão Preto, SP. E-mail: marcobettine@gmail.com

** Doutor em Educação Física. Professor na Faculdade de Educação Física. Departamento de Ciências do Esporte. Área de Concentração: Ciência do Desporto. Unicamp. Campinas, SP, Brasil. E-mail: pcesarm@fef.unicamp.br

*** Professor Titular da Faculdade de Educação Física da Unicamp. (Doutor). Departamento de Educação Motora. Universidade Estadual de Campinas, Campinas, SP, Brasil. E-mail. glgutierrez@terra.com.br
} 
mais importantes daqueles secundários. O passar dos anos, ou das décadas, muitas vezes mostra ao pesquisador que aquelas questões mais recorrentes, tanto nos meios de comunicação como na própria pesquisa, não eram tão significativas assim, enquanto outros aspectos vistos como marginais assumem uma importância muito maior. Outra característica que dificulta a aproximação é o próprio calor do debate, praticamente todas as pessoas envolvidas com o meio acadêmico da Educação Física têm simpatias e amigos num, ou até mesmo vários, dos grupos que participam da discussão sobre a organização do CONFEF.

Mas, mesmo frente a essas dificuldades, parece importante procurar participar da reflexão e contribuir para o seu desenvolvimento, considerando principalmente a sua relevância para a comunidade da Educação Física brasileira. Neste sentido, e tendo sempre presentes as dificuldades que o objeto apresenta, este texto foi estruturado da seguinte forma: inicialmente, discutir-se-á a regulamentação das profissões, em seguida, far-se-á uma análise da lei e das resoluções do CONFEF, enfocando (a) o significado; (b) as atribuições e competências; (c) o limite para a fiscalização e poder de polícia e (d) as atividades típicas do profissional. Posteriormente, o ensaio apontará para os conflitos existentes entre dança, yoga, artes marciais e o CONFEF, apresentando os pontos de vista dos grupos diretamente envolvidos. Para finalizar, apontar-se-á a perspectiva do Conselho e sua relação com a Educação Física.

O estudo tem como objetivo ilustrar e, na medida do possível, contribuir para os debates, os embates, os discursos ${ }^{1}$ e as perspectivas dos sujeitos sociais e instituições envolvidas.

\footnotetext{
1 O método se caracteriza por iniciar dos pontos polêmicos e dar o posicionamento dos sujeitos sociais sobre estes temas a partir de pareceres e artigos. Habermas (1989) propõe a construção de discursos a partir da argumentação dos atores sociais envolvidos numa situação de fala específica, isto é, construindo a visão de mundo e interpretação da situação através das diferentes posições em que os sujeitos se colocam, ora como pesquisador, ora como conseIheiro, ora como profissional. Por isso, este artigo se propõe não como um ponto de vista único, ou uma visão de mundo definida, mas sim como intertexto que articula as diversas argumentações, procurando compreender as ações dos sujeitos e a dificuldade em construir consensos nas diferentes situações de fala. Os sujeitos sociais, nesta situação de conflito, procuram construir seus discursos no plano estratégico de maximização de poder e legitimação unilateral do grupo, abandonando o plano comunicativo, em que poderiam construir formas argumentativas de entendimento, através do respeito mútuo e da busca de soluções consensuais.

Wovimento, Porto Alegre, v. 15, n. 03, p. 275-292, julho/setembro de 2009.
} 


\section{As PROFISSÕES}

A ideia da regulamentação das profissões no Brasil remonta às décadas de 40 a 60 , quando foram regulamentadas atividades como advogado, artista, assistente social, atleta de futebol, bibliotecário, corretor de imóveis e seguros, dentista, economista, empregado doméstico, enfermeiro, engenheiro, arquiteto e agrônomo, estatístico, farmacêutico, fisioterapeuta e terapeuta, geólogo, médico, veterinário, músico, nutricionista, orientador educacional, psicólogo, publicitário, químico, relações públicas, aeronauta, atuário e jornalista. Exatamente trinta profissões regulamentadas apenas nas três décadas citadas, sem contar as que foram regulamentadas recentemente, como a do profissional de educação física, Lei n. ${ }^{\circ}$ 9.696/1998 e as que possivelmente serão, como o Projeto de Lei 7109/06, que regulamentará o profissional de tecnologia da informação.

A regulamentação de uma profissão é um processo notadamente influenciado pela política de controle estatal dos trabalhadores, iniciado pelo Governo Getúlio Vargas. Um dos grandes problemas do período era controlar a classe média nascente, composta pelos profissionais liberais. A saída encontrada foi regulamentar as profissões, trazendo-as para dentro do Estado, com fiscalização e controle.

Com o fortalecimento do Estado, leis foram criadas para construir uma estrutura administrativa eficiente e centralizadora que pudesse controlar a formulação e aplicação de medidas trabalhistas, industriais e sociais. Particularmente na área trabalhista, foi desenvolvida toda uma legislação que ampliou os benefícios sociais, aplicando e fiscalizando leis, e também formas de controle dos sindicatos e dos profissionais liberais (GOULART, 1990). A mesma legislação que garantia os benefícios, também restringia a autonomia sindical e a luta independente dos trabalhadores. Trata-se, portanto, de um período "chave" na relação entre Estado e trabalhadores, em que o Estado apropriou-se do processo de elaboração da legislação do trabalho pretendendo, através dela, desenvolver uma série de contatos com empregados e empregadores, buscando ajustar os interesses em confronto para minimizar os conflitos, fazendo-os participar de uma dinâmica social centralizada.

Movimento, Porto Alegre, v. 15, n. 03, p. 275-292, julho/setembro de 2009. 
Este processo rendeu, por um lado, o almejado controle que o Estado buscava em um momento histórico específico e, por outro lado, permitiu formar uma intelligentsia (elite intelectual) dentro das profissões que se identificaram e se protegeram: (a) frente ao próprio Estado; (b) frente às demais profissões e (c) frente a "leigos" que quisessem "invadir" estas áreas; fechando os grupos dentro dos marcos legais institucionais.

O caminho da regulamentação das profissões apresenta características que nós, educadores físicos, já conhecemos: (a) nunca é consensual, até porque necessita de uma lei que a institua; (b) reserva o direito de exercício profissional; (c) propõem formas de ingresso e pagamento a partir de um diploma; (d) expõe o corporativismo porque o exercício da profissão é fiscalizado pela própria classe e não pela sociedade a quem cabe servir; (e) permite criticas, pelo caráter cartorialista, devido ao pagamento de taxas regulares e a tão famosa reserva de mercado, em que só os afiliados à classe podem exercer a profissão.

Os embates existentes na regulamentação dos educadores físicos são encontrados também, em maior ou em menor grau, nas diferentes profissões. A advocacia, uma das mais antigas profissões regulamentadas, hoje em dia, enfrenta resistência dos seus pares frente ao número de reprovações na prova de habilitação ao exercício profissional, formulada e aplicada pela Ordem dos Advogados do Brasil (OAB). Isso demonstra a dificuldade para construir consensos em espaços em que está em jogo a busca pelo poder, numa dinâmica na qual a representação de um grupo esvazia automaticamente a possibilidade de outros assumirem a direção e o controle da entidade. Procurar consensos para resolver os conflitos da profissão torna-se tarefa árdua, para não dizer impossível, já que os sujeitos sociais envolvidos partem de visões de mundo distintas e tentam impor suas crenças aos outros. Até porque impor sua visão de mundo permite, no limite, constituir-se como representante legal de toda uma classe e isso dá acesso a status e poder (HABERMAS, 1989).

\section{CAMINHO dA REGULAMENTAÇÃo dA EDUCAÇÃO FíSICA (E.F.): EMBATES}

O caminho da regulamentação da E.F. construiu-se durante anos. Só para recordar, no Governo Sarney, os professores Inezil

Movimento, Porto Alegre, v. 15, n. 03, p. 275-292, julho/setembro de 2009. 
Penna Marinho, Manuel Tubino e Valter Giro Giordano, tiveram o Projeto de Lei da regulamentação da profissão aprovado na Câmara e no Senado, para ser finalmente vetado pelo Presidente, com a justificativa de que os professores estavam subordinados ao MEC e, por isso, já estariam devidamente controlados. Após esse acontecimento, um grupo de profissionais liderado pelo Prof. Jorge Steinhilber, primeiro e único presidente do CONFEF, 1998-2009, ergueu a bandeira em favor da regulamentação que culminou na aprovação dessa proposta no plenário do Congresso Brasileiro de Profissionais de Educação Física, instância máxima de representação profissional, em dezembro de 1994 (STEINHILBER, 1998). Em 1987, com a edição do parecer que resultou na criação do bacharelado em educação física, surgiu um espaço de atuação profisssional que não era regulado pelo Ministério da Educação e Cultura (MEC) à época. Aproveitando esse espaço, o Movimento a favor da Regulamentação conseguiu aprovar, na Comissão de Constituição e Justiça, o Projeto de Lei n ${ }^{\circ}$ 330-C (MASCARENHAS, 1995), de 1996, que se transformou, com algumas alterações (MONTEIRO, 2006) como a exclusão da dança, na Lei 9696/98.

Marco jurídico na transformação da situação da profissão dos educadores físicos, o $\mathrm{CONFEF}^{2}$ constitui-se como autarquia de regime especial, uma entidade civil sem fins lucrativos, com sede e foro na cidade do Rio de Janeiro, destinado a orientar, disciplinar e fiscalizar o exercício das atividades próprias dos profissionais de Educação Física. Com este texto legal, buscou-se regulamentar o exercício profissional do educador físico na área de Educação Física e, também, designou o Profissional de Educação Física como sendo o único que possui prerrogativa para atuar nesta área, com a condicionante de ser registrado num Conselho Regional de Educação Física (CREF).

A ideia principal era limitar quem poderia atuar na área de Educação Física, afirmando que apenas poderão operar os profissionais

\footnotetext{
${ }^{2}$ Dentro deste contexto administrativo, destacam-se os Conselheiros Federais para o CONFEF e os Conselheiros Estaduais para os CREFs, eles têm a responsabilidade de fazer cumprir o Código de Ética da Profissão, representar o Conselho nos diversos eventos e legislar, dentro de suas atribuições, sobre as regras adotadas nos Conselhos para os profissionais. CONFEF (2002).

Movimento, Porto Alegre, v. 15, n. 03, p. 275-292, julho/setembro de 2009.
} 
registrados nos CREF. Coloca, assim, o critério de ingresso no exercício profissional sob fiscalização e decisão do Conselho. O grupo favorável à regulamentação defendeu a necessidade de proteger o mercado de trabalho, já que pessoas sem uma formação adequada intervinham nas diferentes áreas que o educador físico atuava, faltando, muitas vezes, postos de trabalho. Com esse instrumento jurídico, é possível minimizar os problemas pertinentes à área de educação física na condução da atividade, afastando os leigos, ex-praticantes e curiosos. $^{3}$

Outro ponto importante refere-se à qualidade da atividade desenvolvida. Afirmava-se que as aulas de E.F. tinham pouca qualidade, porque muitos dos profissionais não tinham qualquer formação específica para instrução e monitoramento na execução de atividades físicas. A regulamentação da profissão também seria importante para a sociedade, protegendo os usuários, pois, a partir de 1998, ele saberia que só uma pessoa regulamentada estaria promovendo aquela atividade e estabelecer-se-ia uma ética profissional (REPPOLD FILHO, 2003).

Os defensores ${ }^{4}$ da regulamentação e do Conselho salientam a importância da especialização do saber e a busca contínua de conteúdos exclusivos para a área. Desta forma, o profissional de Educação Física se constituiria no titular da atividade física, como o advogado, o médico, o psicólogo ou o enfermeiro é titular das suas profissões. Para formar uma intelligentsia perante a sociedade, e às outras profissões já constituídas, endossam a necessidade da criação de um Conselho profissional, junto com um código de ética. Essas iniciativas, dentro da lógica que rege a regulamentação, são essenciais para estabelecer padrões de conduta profissional, assegurar o oferecimento de um serviço de alta qualidade e a projeção de uma

\footnotetext{
${ }^{3}$ Steinhilber (1998) afirma: a profissão não deve ser exercida por diletante. O simples acúmulo de conhecimentos empíricos ou a marca de algum talento individual não são predicados suficientes para o bom e correto desempenho da profissão.

${ }^{4}$ Sinteticamente, pode-se apresentar os seguintes nomes e documentos contrários à regulamentação: - Reflexões acerca da regulamentação da profissão e Day After (LINO CASTELLANI FILHO); O velho problema da regulamentação (ALFREDO GOMES DE FARIA JUNIOR; CARLOS FERNANDO FERREIRA DA CUNHA JUNIOR; HAGIME TAKEUCHI NOZAKI; VICTOR ANDRADE DE MELO).

Wovimento, Porto Alegre, v. 15, n. 03, p. 275-292, julho/setembro de 2009.
} 
imagem profissional. A regulamentação permite que um instituto legal proteja uma área vulnerável à atuação de indivíduos não profissionais.

O Professor Barros comenta que a legalização não é um instrumento que garante a melhoria da qualidade profissional. Isto só deverá ocorrer através da atuação do profissional, da sua consciência, da formação e dos princípios que norteiam sua ética. Deste modo, o Conselho profissional teria, dentre outras funções, a de assegurar os nichos específicos e exclusivos do profissional da área (BARROS, 2000, p. 108-109). Pode-se concluir, desta abordagem, que os profissionais favoráveis à regulamentação sustentam algumas "verdades": a primeira delas é que ser regulamentado transformou-se em sinônimo de qualidade e competência; segundo, ter um grupo fiscalizador infere uma ética profissional e, por último, ter profissionais habilitados é garantia de segurança à população.

Grupos contrários à regulamentação da profissão apontam o livre exercício profissional como forma de desenvolver, nos trabalhadores, a consciência de classe e sustentam que a visão do mercado, o cartorialismo, o corporativismo e o modelo neoliberal são a base para a lógica da regulamentação (NOZAKI, 2004). Partindo de uma matriz teórica marxista, a união dos trabalhadores para combater o capital tornar-se-ia mais difícil com a regulamentação, já que assim cada área específica se volta para resolver os problemas de seu grupo, criando formas internas de perpetuação do poder que tendem a dificultar o desenvolvimento da consciência de classe.

Nozaki e Faria Junior (2004) apontam que a regulamentação da profissão traduz uma ideia privatista de Educação Física, por apoiar o crescimento de cursos em Faculdades privadas e bacharelados; argumentam ainda que o bacharelado sintetiza a ideia, da década de 1970, de valorização da atividade física frente a uma concepção de educação transformadora (FARIA JUNIOR, 1993). Nesta óptica, o CONFEF surge como forma de adaptação da E.F. à sociedade capitalista (SILVA; LANDIM, 2003). Outras colocações dos grupos que se posicionam contrariamente à regulamentação da profissão, como o Movimento Nacional Contra a Regulamentação (MNCR), em 2007, que aponta para questões que incidem particularmente sobre

Movimento, Porto Alegre, v. 15, n. 03, p. 275-292, julho/setembro de 2009. 
o Sistema CONFEF/CREF, como a falta de esclarecimento de seus objetivos; a tentativa de retomada de espaço político pelos setores conservadores da Educação Física; resoluções da profissão constituídas em reuniões restritas, tais como o código de ética, chapa, estatuto, estágio extracurricular e, por último, a definição do paradigma da Educação Física como aptidão física. Para discutir melhor esses pontos, é necessário ilustrar rapidamente a estrutura legal do Sistema CONFEF/CREF.

\section{AESTRUTURA DO SISTEMA CONFEF/CREF}

O primeiro artigo da Lei 9696/98 aponta para o CONFEF como órgão da administração pública, autarquia criada por lei para regulamentar o registro e fiscalizar ${ }^{5}$ os locais onde atuam os profissionais de E.F. O poder de fiscalização e de polícia é típico das autarquias, porém esse poder deve ser sustentado pelo Ministério Público (MP) e órgãos do Poder Executivo, como parceiros nas diligências. ${ }^{6}$

Uma das questões mais controversas refere-se a quem poderá exercer a educação física de forma profissional. Outro aspecto central refere-se ao que fazer daqueles que trabalhavam como educadores físicos antes da vigência da lei. No art. $2^{\circ}$, encontra-se a resposta para esta polêmica. Determina-se que apenas serão inscritos nos quadros dos CREF os possuidores de diploma obtido em curso de Educação Física oficialmente autorizado ou reconhecido e os que, até a data do início da vigência desta lei, tenham comprovadamente exercido atividades próprias dos Profissionais de Educação Física, ${ }^{7}$ nos termos

\footnotetext{
${ }^{5}$ Os números divulgados no site do Conselho dão uma ideia da fiscalização e atuação do CONFEF (até o ano de 2006). Recebidas: 3.675 denúncias; notificados: 12.892 estabelecimentos comerciais e/ou profissionais que não atuavam de acordo com o Código de Ética ou pessoas que exerciam irregularmente a profissão. Para este montante, foram envolvidos cerca de 645 municípios e dessas notificações, 2.155 foram enviados para o Ministério Público (MP) para autuar e exercer seus poderes investigativos, levando a 766 audiências em que o MP tomou o polo ativo da demanda. E, por último, lembra que foram feitas 17.304 fiscalizações em loco, sendo 6.658 novas visitas e 10.646 revisitas.

${ }^{6} \mathrm{Na}$ resolução ${ }^{\circ} 23 / 2000$, no art. $5^{\circ} \mathrm{d}$, o Conselho fiscaliza, e deve denunciar a outras autoridades competentes as irregularidades encontradas e não corrigidas dentro dos prazos, mostrando que essa resolução cumpre os requisitos legais (CONFEF, 2002).

${ }^{7}$ Os não formados recebem as carteiras de provisionados, como técnico de uma determinada área, mas não nivelado ao formado, porém respondendo da mesma maneira.

Wovimento, Porto Alegre, v. 15, n. 03, p. 275-292, julho/setembro de 2009.
} 
a serem estabelecidos pelo CONFEF. Com o projeto de lei em tramitação no Senado Federal, os senadores propuseram uma emenda (inciso III, art. $2^{\circ}$ ) que possibilitou aos profissionais que já exerciam atividades próprias dos educadores físicos, antes da promulgação da lei, receber do conselho uma autorização com algumas particularidades para trabalhar naquilo que já faziam anteriormente.

O legislador deu ao CONFEF poderes para determinar de que forma esses profissionais não formados, mas que exerciam funções dos profissionais de educação física, poderiam garantir o seu direito adquirido. Assim o conselho editou algumas resoluções sobre o tema, dentre as quais se destaca a Resolução 045/2002 que determina a frequência a um programa orientado pelo CREF para conseguir o registro profissional dos não graduados em curso superior de Educação Física.

Depois de determinar quem seria a entidade administrativa (autarquia) responsável pela regulamentação profissional e, também, quem poderia regulamentar, o legislador descreveu exaustivamente a competência e as áreas em que o sujeito regulamentado poderia atuar e, principalmente, exercer o seu direito de ter atividades privativas ao profissional regulamentado. O rol é taxativo, isto é, exaure-se em si mesmo, porque a lei que dá direito a grupos específicos, como é o caso do exercício da profissão, em detrimento da coletividade, deve ser analisada de forma restritiva. Deste modo, no art. $3^{\circ}$ descreve-se que compete ao Profissional de Educação Física "[...] coordenar, planejar, programar, [...], realizar treinamentos especializados, [...], todos nas áreas de atividades físicas e do desporto". (CONFEF, 2002). Duas questões devem ser postas neste momento. Primeiro, na área escolar indagou-se sobre a competência do Conselho para regular as atividades dos professores do ensino formal. Como o rol é taxativo, não podendo resolução interna afrontar o dispositivo legal, não resta suspeita que não é competência do CONFEF atuar nas atividades de docência do ensino formal. A segunda questão refere-se à dança; ela é área de atividade física e desporto?

Mesmo tendo esta interpretação restritiva, o Conselho por meio da Resolução $n^{\circ}$ 046/2002, dispôs sobre a Intervenção do Profissional de Educação Física dando uma certa dubiedade à letra legal e

Movimento, Porto Alegre, v. 15, n. 03, p. 275-292, julho/setembro de 2009. 
ampliando em demasia o rol taxativo, o que gerou protestos de vários segmentos que trabalham com o corpo, como a capoeira, a dança, as artes marciais, o circo e a docência formal. ${ }^{8}$ De acordo com a resolução apontada, o profissional de Educação Física é especialista em atividades físicas, nas suas diversas manifestações, como: ginásticas, exercícios físicos, desportos, jogos, lutas, capoeira, artes marciais, danças, ioga, exercícios compensatórios à atividade laboral e do cotidiano e outras práticas corporais. É importante perceber que a atividade física e o desporto colocados na lei deram lugar, nesta resolução, a práticas corporais. Muito mais abrangente "prática corporal" engloba tudo que movimenta ou intervêm no corpo. Não é fácil compreender precisamente os objetivos do Conselho ao ampliar os espaços de intervenção. É uma adequação ao modelo teórico da Motricidade Humana ou apenas mais uma forma de reprodução e ampliação do seu espaço de influência?

Voltando aos aspectos legais da lei $9696 / 98$, no seu art. $4^{\circ}$, foram criados, ao mesmo tempo, o Conselho Federal e os CREF. Questionase a possibilidade de uma lei federal permitir que a entidade superior CONFEF crie entidades subordinadas CREF'S. Em outras palavras, deveria haver uma lei que regulamentasse o CONFEF, e outras, em separado, que criariam os Conselhos Regionais em cada Estado da Federação. No entendimento dos juristas do Direito Administrativo, Hely Lopes Meirelles e Celso Antonio Bandeira de Mello, isto é possível devido ao princípio da hierarquia da Administração Pública, em que a entidade diretamente vinculada à administração pública, a autarquia superior, constitui entidades inferiores para melhor atingir os objetivos expressos na lei, já que ela, autarquia primeira criada em lei, é que responde subsidiariamente por qualquer desvio de finalidade das suas entidades inferiores.

\footnotetext{
${ }^{8} \mathrm{Na}$ especificação profissional que é disciplinada pelo art. $2^{\circ}$ da resolução $046 / 2002$, fala-se da regência/docência em E.F. Ficou o questionamento sobre a competência do CONFEF em ampliar as áreas de intervenção. O princípio da hierarquia das leis afirma que uma resolução normativa tem apenas efeito nos limites daquela entidade administrativa e não tem efeito erga omnes (contra todos). Isto ocorreu com a resolução 046/2002 que alcançou profissionais de áreas que não são diretamente relacionados a E.F. e não são regidos pelo art. $2^{\circ}$ da Lei $9696 / 98$, logo parece que se deve minimizar os efeitos da resolução ora mencionada.
}

Movimento, Porto Alegre, v. 15, n. 03, p. 275-292, julho/setembro de 2009. 
Outra resolução que gerou discussão nos meios acadêmicos, e ampliou as dúvidas sobre os objetivos e as decisões do Conselho, foi a Resolução n 23/2000 que regula a fiscalização das pessoas jurídicas. Esta resolução descreve as formas de fiscalização dos profissionais e das Pessoas Jurídicas que oferecem atividades, o que está em pleno acordo com as regras das autarquias no Direito Administrativo. Mas, um fato chama a atenção nessa resolução, a cobrança de anuidade das Pessoas Jurídicas. A resolução determina o registro e pagamento de empresas prestadoras de serviços em atividades físicas, desportivas e similares, em cumprimento ao previsto no inciso IV, art. 56, do Estatuto do CONFEF. Este instituto não tem previsão legal. O Conselho argumenta que as empresas prestadoras de serviços em atividades físicas, ao assumirem a responsabilidade da atividade física para os beneficiários, direta ou indiretamente, têm o dever legal de assegurar que as prestações desses serviços sejam procedidas de forma ética, sob a responsabilidade de profissional de Educação Física devidamente registrado no Conselho. O que é de pleno direito, no entanto, a pessoa jurídica prestadora de serviço é regulada por leis próprias (Direito Comercial) e não por regimento do Conselho, portanto não deveria pagar anuidade.

\section{PolÊMICA dA AMPLIAÇÃo dA ÁREA dE ATUAÇÃo DOS EDUCADORES FÍSICOS: DEBATES}

Após a publicação da Resolução n ${ }^{\circ} 046 / 2002$, que ampliou as áreas de atuação de E.F. e, consequentemente, diminuiu o espaço de outros profissionais, houve uma grande manifestação contrária. Os profissionais de dança, principalmente, se posicionaram contra a colocação da dança como área privativa da E.F. afirmando que o CONFEF é incompetente para legislar, fiscalizar, orientar e emitir normas sobre outra categoria profissional que não está agregada por lei à sua área. Uma das consequências destes protestos foi o Projeto de Lei 7370/02, do deputado Luiz Antonio Fleury, que exclui da fiscalização dos conselhos federal e regional de Educação Física os profissionais de dança, lutas marciais, yoga e capoeira. Estes profissionais estão buscando a sua aprovação, tendo em vista o impedimento da regulamentação

Movimento, Porto Alegre, v. 15, n. 03, p. 275-292, julho/setembro de 2009. 
das suas atividades pelo CREF e CONFEF. Parece que o fenômeno de regulamentação atinge, cada vez mais, um alto grau de especialização, que levará à ampliação das profissões regulamentadas.

Há uma tensão entre os profissionais da dança e educação física. Os intelectuais e professores de dança consideram os profissionais da Educação Física incapacitados para trabalhar seus conteúdos, por o fazerem, geralmente, de maneira acrítica e superficial, enfatizando a abordagem tecnicista. Os profissionais da Educação Física, por sua vez, se consideram no total direito para ministrá-los, devido à sua formação acadêmica, por ter estudado anatomia, cinesiologia, atividades expressivas e lidar diretamente com o movimento. Deve-se lembrar que esses conflitos resistem ao tempo, já que o primeiro projeto de lei colocava sob o mesmo conselho os profissionais de dança e educação física.

Os profissionais de dança alegam que o único motivo para a ampliação da área é aumentar a reserva de mercado da E.F. ${ }^{9}$ Por isso, a Ação Civil Pública no Distrito Federal. Nos autos do processo, foram juntados currículos de diferentes universidades, tanto da Educação Física como da Dança, e decidiu-se que os profissionais de dança possuem um conhecimento especializado e têm maior competência para atuar na área em detrimento dos educadores físicos. O Julgado atingiu a resolução 046/2002 por inteiro, já que, segundo o Juiz de Direito, a resolução exorbitou os limites legais da lei que criou a autarquia.

A maior crítica dos grupos que não concordam com a regulamentação da profissão refere-se à concepção da atividade física (qualquer movimento humano). Assim, para o CONFEF, toda e qualquer atividade como dança, ioga, ou lutas subordinam-se à sua atuação (MNCR, 2007).

Quem pratica dança, para alguns dos seus professores (SARAIVA, 2005), seja por profissão ou lazer, não objetiva um aumento de massa muscular, de flexibilidade corporal ou de capacidade aeróbia.

\footnotetext{
${ }^{9}$ Fato este confirmado na Sentença $n^{\circ} 2005 / J R J O / J F / D F-14^{a}$ Vara, Autos n ${ }^{\circ}$ 2001.34.00.0315823, Ação Civil Pública, proposta pelos profissionais de dança no DF.

Wovimento, Porto Alegre, v. 15, n. 03, p. 275-292, julho/setembro de 2009.
} 
Na dança, a atividade física é apenas um meio para o exercício de uma arte que, em muitos casos, representa típica manifestação da cultura brasileira. Yoga, por sua vez, é uma atividade que busca o equilíbrio mental e corporal por meio de exercícios basicamente de respiração e de concentração, não envolvendo atividade física, já que é uma filosofia e não uma modalidade esportiva. As artes marciais (karatê, judô, tai chin chuan etc.) embora naturalmente envolvam movimentação corporal, não são atividades próprias do profissional de educação física. Antes de ser atividade corporal, as artes marciais e a Yoga possuem ensinamentos que refletem culturas milenares. Neste caso, tem-se dois pensamentos sobre o tema (JUNIOR; DRIGO, 2001), o primeiro aponta para a raridade dos cursos de graduação em educação física que possuem, na sua grade, a estrutura formativa necessária para o conhecimento do universo cultural das artes marciais, o segundo pensamento discorre sobre as invasivas sessões de treinamento, ministradas, em geral, por ex-atletas. As opiniões são divergentes e apontam para interpretações equívocas do mesmo fenômeno.

Em que pese os conflitos que surgiram após a resolução supra citada, a relação Dança e Educação Física é mais complicada do que simplesmente dizer que a Educação Física prioriza a atividade física, e a dança é arte (PACHECO,1999). A obra de Soares (1992) já afirmava que a dança é um conteúdo da Educação Física escolar, assim como o jogo, o esporte, a ginástica e a capoeira. É difícil dizer com certeza se a ampliação da área de atuação é algo incidental ou fruto de discussões que permearam a Educação Física e a Dança nestas últimas décadas.

A exigência da carteira expedida pelo CREF para o exercício da docência formal (na Educação Física Escolar) foi deferida numa ação liminar no RJ. ${ }^{10} \mathrm{O}$ diploma de licenciado é suficiente para a prática da docência. ${ }^{11}$

${ }^{10}$ Número 2003.5101019004-0 , Ação Civil Pública .

${ }^{11}$ Neste sentido, editou-se uma lei estadual $n^{\circ} 11.361 / \mathrm{SP}$, no seu Art. $2^{\circ}$, afirmando que "Somente profissionais devidamente habilitados, portadores de licenciatura plena em educação física, podem ministrar a disciplina de Educação Física". Pode-se destacar outros pareceres que vão contra a regulamentação de docentes (PARECER N 75/99/COJUR/MEC; PARECER PJ Nº04/2000).

Movimento, Porto Alegre, v. 15, n. 03, p. 275-292, julho/setembro de 2009. 
No entanto, o debate e os argumentos se multiplicam. As revistas do CONFEF $(2002,2001)$ salientam que, apesar da determinação da justiça garantir aos profissionais de dança, yoga e artes marciais a não necessidade de inscrição no $\mathrm{CREF}$, apenas os registrados e diplomados em E.F. têm conhecimento suficiente para ser um professor ou orientador dessas atividades.

Monteiro (2006), discutindo a temática, apresenta o posicionamento do Sr. José Maria de Camargo Barros, Conselheiro de Legislação e Normas do CONFEF, acirrando ainda mais os pontos de vista. O conselheiro afirma que a Educação Física foi regulamentada como profissão com um conceito bastante amplo, procurando atender as necessidades da sociedade. Dentro do conceito de Educação Física, a Dança, as Artes Marciais e a yoga estão inclusas. Continua o conselheiro: "O que você pretende quando faz yoga, Arte Marcial, Futebol? É atender as necessidades de movimento, de recreação, de revigoramento, de liberação psicológica corporal, entre outros fatores, esta é a razão da realização destes exercícios".

Para esse Conselheiro do CONFEF, a falta de entendimento sobre o conceito atividade física ocorre pelos diferentes referenciais teóricos adotados na Educação Física. $\mathrm{O}$ conceito de educação física ou atividade física adotado pelo CONFEF, segundo José Maria de Camargo Barros, parte da teoria de Manuel Sérgio, Motricidade Humana (1989). O termo motricidade humana define-se como a capacidade e necessidade de que o ser humano tem de transcender o movimento para viver. A prática da atividade física significa conhecer os movimentos e os controles neuromotores desses movimentos. Segundo esta visão, é a partir daí que o profissional da motricidade humana conseguirá fazer análise dos movimentos, interferindo e contribuindo para o desenvolvimento das atividades físicas. Como é uma concepção bastante ampla, torna difícil discutir o que não seria Motricidade Humana.

\section{A REGULAMENTAÇÃO DA PROFISSÃO: PERSPECTIVAS}

Como foi destacado no início, o tratamento de um objeto de pesquisa recente e polêmico apresenta muitas dificuldades para o

Movimento, Porto Alegre, v. 15, n. 03, p. 275-292, julho/setembro de 2009. 
pesquisador. Sem perder de vista que o processo pode vir a sofrer grandes transformações muito rapidamente, pode-se imaginar que os Projetos de Lei ${ }^{12}$ de Paulo Paim e Luiz Antonio Fleury Filho finalizarão a polêmica com outras áreas, determinando, em resumo, a exclusão do registro e da fiscalização pelos CONFEF: (a) dos professores habilitados, registrados e admitidos ao trabalho na forma de legislação de ensino vigente, desde que exerçam somente atividades docentes; (b) dos mestres, instrutores e monitores de iniciação e especialização desportiva e da cultura física credenciados, registrados e fiscalizados por suas federações e confederações; (c) dos profissionais da dança, artes marciais, yoga, capoeira e circo.

Ainda no campo das expectativas, caso não seja aprovado projeto de lei descrito anteriormente, as duas ações civis públicas poderão legalizar (restringindo ou mantendo) as resoluções de ampliação da área de abrangência e fiscalização do CONFEF ou, em um cenário mais drástico, os desembargadores podem declarar a inconstitucionalidade do Sistema CONFEF/CREF, extinguindo-o do mundo jurídico.

A tendência mais provável é que a regulamentação da profissão continue a ser lei e os profissionais continuem se credenciando no CREF, por determinação legal. Inclusive porque é sabido que a maioria dos profissionais regulamentados está distante das discussões que permeiam a regulamentação da profissão, ficando os debates restritos ao meio acadêmico e espaços de disputa de poder como Secretarias da União, Estados e Municípios.

Faria Junior (2001) aponta que a regulamentação não atingiu seus objetivos por ter se sedimentado apenas em algumas regiões do Brasil, como demonstra o fato de que o número dos profissionais registrados nos Conselhos é inferior ao número de formandos anuais, nos mais de 200 cursos e escolas de educação física do país. Mesmo sem conhecer algum estudo que valide a afirmativa e além do fato dos números não separarem licenciados e bacharéis, parece correto afirmar que existe uma dificuldade para difundir o Conselho por todo o território brasileiro, frente às desigualdades entre regiões e a grandeza

\footnotetext{
12 Projeto de Lei 3559/2002 - Paulo Paim e Projeto de Lei 7370/2002 - Luiz Fleury Filho.
}

Movimento, Porto Alegre, v. 15, n. 03, p. 275-292, julho/setembro de 2009. 
do país. No entanto, o argumento mais forte é que o próprio bacharelado de educação física não possui grande inserção nas regiões menos favorecidas, onde não existe muito investimento privado na área da atividade física. Neste cenário, a perspectiva é de aumento da influência do CONFEF, na medida em que ocorra um maior desenvolvimento regional e mais investimentos na área de atuação do bacharel.

Outro fato que poderá fortalecer o Conselho é o aumento de litígios entre profissionais e clientes. Com o número crescente de ações na justiça, caberá ao Conselho, como braço do poder público, proteger o profissional e balizar a decisão jurídica com pareceres, peritagens e aconselhamentos. Quando iniciarem estes litígios o Conselho terá muito mais visibilidade na comunidade. ${ }^{13}$

Finaliza-se este ensaio reafirmando a importância de ampliar as discussões para além dos muros das universidades, já que do modo em que hoje se apresentam os discursos, apenas reproduzem a palavra estanque dos mesmos grupos, de um lado e de outro, levantado as mesmas bandeiras, com os mesmos argumentos. A intenção com este texto, portanto, é incentivar a ampliação do debate e atrair novos participantes para este campo de discussão e reflexão.

\begin{tabular}{|l|}
\hline The insertion of the regulation of the profession \\
in the area of physical education, ten years later: \\
perspectives, strike and debates. \\
Abstract: This text argues some questions contro- \\
versies on the regulation of the profession. Our interest \\
is to give a theoretical basement of a side, and to hear \\
the citizens directly related on these controversies of \\
another one. For this we first decide to clarify the initial \\
aspects of the regulation of the professions, stops later \\
making an analysis of the law and resolutions of the \\
Advice presenting: (a) the meaning; (b) attributions and \\
abilities; (c) the limit for the fiscalization and of the power \\
of polices and (d) to point the typical activities of the profes- \\
sional. Concluded this part we will raise an controversial \\
subject that appeared in these last five years: the \\
subordination of the dance, yoga, martial arts to the Fe- \\
deral Advice of Physical Education. \\
Keywords: Professional practice. Physical Education. \\
Specialty boards.
\end{tabular}

${ }^{13}$ Projeto de Lei 3559/2002 - Paulo Paim e Projeto de Lei 7370/2002 - Luiz Fleury Filho.

Movimento, Porto Alegre, v. 15, n. 03, p. 275-292, julho/setembro de 2009. 


La inserción de la regulación de la profesión en
el área de la educación física, diez años después:
embates, debates y perspectivas.
Resumen: Este texto discute las controversias sobre
la regulación de la profesión. Nuestro interés es dar un
suporte teórico de un lado, y oír a los ciudadanos rela-
cionados directamente en estas controversias de otro.
Para esto primero, decidimos clarificar los aspectos ini-
ciales de la regulación de las profesiones, un análisis
de la ley y de las resoluciones del consejo: (a) el signi-
ficado; (b) atribuciones y capacidades; (c) el límite para
el fiscalización y poder de policía y (d) señalar las acti-
vidades típicas del profesional. Después de esta parte
levantaremos un tema polémico: la subordinación de la
danza, yoga, artes marciales al consejo federal de la
educación física.
Palabras clave: Práctica profesional. Educación Físi-
ca. Consejos de especialidades.

\section{REFERÊNCIAS}

BARROS, J. M. Educação física, profissão regulamentada. Revista Brasileira de Ciência do Esporte, São Paulo, v.21, n.2/3, p. 108-109, 2000.

CONFEF. Capoeira. Revista do CONFEF, Rio de Janeiro, n. 01, nov. 2001.

. Dança. Revista do CONFEF, Rio de Janeiro, n. 02, mar. 2002.

FARIA JUNIOR, A. O velho problema da regulamentação: contribuições e críticas. Revista Brasileira de Ciências do Esporte, Florianópolis, v.17, n.3, p. 266-272, 1996.

Reflexões sobre a educação física brasileira: a carta de Belo Horizonte. Revista Brasileira de Ciências do Esporte, Campinas, v.23, n.1, p. 19-33, 2001.

GOULART, S. Sob a verdade oficial: ideologia, propaganda e censura no Estado Novo. São Paulo: Marco Zero, CNPq, 1990.

HABERMAS, J. Consciência moral e agir comunicativo. Rio de Janeiro: Tempo Brasileiro, 1989.

JUNIOR, L; DRIGO, A. A já regulamentada profissão de educação física e as artes marciais. Motriz, Rio Claro, v.7, n.2, p. 131-132, 2001.

MASCARENHAS, E. Projeto de Lei $n^{\circ} 330-C / 95$. Anais do Congresso Nacional da República Federativa do Brasil. Brasília, 1995.

MOVIMENTO CONTRAAREGULAMENTAÇÃO PROFISSIONAL (MCRP). Manifesto contra a regulamentação do profissional de educação física, pela revogação da lei 9696/98. Disponível em: http://mncr.Rg3.net. Acesso em 17 de julho 2007.

Movimento, Porto Alegre, v. 15, n. 03, p. 275-292, julho/setembro de 2009. 
MONTEIRO, R. A. Educação Física: história, política e atualidade incerta. Efdeportes - Revista Digital, Buenos Aires, v.10, n.93, fev. 2006. Disponível em http:// www.efdeportes.com/. Acesso em: 20 dezembro 2007.

NOZAKI, H. Educação Física e reordenamento no mundo do trabalho: mediações da regulamentação da profissão. 2004. Tese (Doutorado) - Universidade Federal Fluminense, Niterói: UFF, 2004.

PACHECO, A. J. P. A Dança na Educação Física: uma revisão da literatura. Revista Brasileira de Ciências do Esporte, São Paulo, v. 21, n. 1, p. 117-124, 1999.

REPPOLD FILHO, A. R. . Código de Ética Profissional: Considerações Históricas e Filosóficas. In: Seminário de ética da Educação Física, 2. 2003, Foz do Iguaçu: Conselho Federal de Educação Física, 2003.

SANTOS, D. R. A responsabilidade jurídica por lesões em atividade física nas academias de ginástica. Jornal de Medicina do Exercício, Rio de Janeiro, 2003.

SARAIVA, M. O Sentido da Dança: arte, símbolo, experiência vivida e representação. Movimento, Porto Alegre, v. 11, n.3, p. 219-242, 2005.

SERGIO, M. Educação física ou Ciência da Motricidade Humana? Campinas, SP: Papirus, 1989.

SILVA, M.; LANDIM, R. Os impactos da regulamentação da profissão de Educação Física na prática pedagógica. Revista do Mestrado em Educação, Sergipe, v.7, p. 79-94, 2003.

SOARES, C. L. et al. (org.) Metodologia do Ensino da Educação Física. São Paulo: Cortez, 1992.

STEINHILBER, J. A Postura Profissional Ética: a contribuição do Sistema CONFEF/ CREFs. In: Fórum Nacional das Instituições de Ensino Superior em Educação Física, 2. Rio de Janeiro. Anais... CONFEF, Rio de Janeiro, 2002.

. Pontos, contrapontos e questões pertinentes à regulamentação do profissional de educação física. Motriz, Rio Claro, v. 4, n.1, p. 12-21, 1998.

Recebido em: 04.03.2008

Aprovado em: 26.03.2009

Movimento, Porto Alegre, v. 15, n. 03, p. 275-292, julho/setembro de 2009. 